\title{
Māori Pain Experiences and Culturally Valid Pain Assessment Tools for Māori: A Systematic Narrative Review
}

\author{
Tobias J. Hoeta \\ Undergraduate student, School of Physiotherapy, University of Otago, Dunedin, New Zealand
}

G. David Baxter TC, BSC (Hons), DPhil, MBA, FCSP

Centre for Health, Activity and Rehabilitation Research, School of Physiotherapy, University of Otago, Dunedin, New Zealand

Katrina A. Pōtiki Bryant BPhty, PGDip, MPhty

Kaiārahi Māori/Professional Practice Fellow, School of Physiotherapy, University of Otago, Dunedin, New Zealand

Ramakrishnan Mani DAc, BPhty, MPhty, PGCert, PhD

Senior Lecturer, Centre for Health, Activity and Rehabilitation Research, School of Physiotherapy, University of Otago, Dunedin, New Zealand

\section{ABSTRACT}

Physiotherapists in Aotearoa New Zealand use various models and tools for assessing pain, many of which have been developed and validated in other ethnic populations outside Aotearoa New Zealand. In particular, assessing pain within the Māori population should be culturally appropriate and capture Māori realities associated with pain experience. The purpose of this systematic review was three-fold: to explore evidence of pain experiences among Māori, to identify any pain assessment questionnaires that capture Māori experiences of pain, and to propose a framework to evaluate the adherence to kaupapa Māori research guidelines. Due to the gap in the literature, only two studies were eligible. Based on these two studies, whānau, Māori holistic views of health, whakapapa, and spirituality were identified as key themes associated with Māori pain experiences. The quality of included studies was "medium-high" and "high". The overall evaluation based on the Confidence in the Evidence from Reviews of Qualitative research demonstrated "high-moderate" confidence in the findings. Evaluation of adherence to a kaupapa Māori theory framework of the included studies found these to be limited. This review could not identify culturally valid tools to capture Māori experiences of pain, and established the need to develop tools encompassing themes associated with Māori experiences of pain.

\section{Hoeta, T. J., Baxter, G. D., Pōtiki Bryant, K. A., \& Mani, R. (2020). Māori pain experiences and culturally valid pain assessment tools for Māori: A systematic narrative review. New Zealand Journal of Physiotherapy, 48(1), 37-50. https:// doi.org/10.15619/NZJP/48.1.05}

Key Words: Pain Experience, Māori, Indigenous, Pain Perception, Pain Assessment

\section{INTRODUCTION}

Chronic pain among general populations is a major burden on individuals, the healthcare system, and society (Briggs et al., 2016; Smith et al., 2014). In Aotearoa New Zealand one in five adults $(21 \%)$ is reported to be living with chronic pain, the rate rising steeply with an ageing population (Ministry of Health, 2015). Of note, the rate of chronic pain within the Māori population, the indigenous peoples of Aotearoa New Zealand, is higher than that of non-Māori (statistically significant adjusted ratio of 1.2) (Ministry of Health, 2015). This may be due to a number of complexities, such as access to health care, quality of health care and racial discrimination (Harris et al., 2006).

Pain experience can be affected by multiple different factors, such as psychological (e.g., attitude and beliefs, and mood disorders), social, cultural, spiritual factors, and early life stress events (Linton, 2011). Ethnicity and/or race have also been reported as an influencing factor on the pain experience (Green et al., 2003). Many Māori view health holistically, connecting physical, mental, social, and spiritual health dimensions together (Rochford, 2004); when one of these domains is affected, so are the rest (e.g., when feeling mentally strong, you are able to support others who are less so through social support and interaction). Understanding the lived experiences of pain among Māori is an important aspect to consider and to address in clinical practice (Pitama et al., 2011; Shipton, 2013). Understanding the kaupapa Māori theory (KMT) would also help enrich such an understanding, and help to develop culturally appropriate physiotherapy practice when assisting Māori living with pain. As the KMT is underpinned by Māori worldviews, it would be helpful using this framework to understand how these contexts are affected during pain experiences and provide effective care for Māori.

Currently, physiotherapists in Aotearoa New Zealand and the Accident Compensation Corporation (ACC), as a primary services funder, use various models and tools for measuring pain. Many of these models have been developed and tested for cultural appropriateness (evidenced-based) in countries other than Aotearoa New Zealand (Brady et al., 2016). To effectively manage chronic pain, assessment tools need to be relevant for the population being assessed (Breivik et al., 2008). Given that Māori are indigenous to Aotearoa New Zealand, it is pertinent that assessment measures used in Aotearoa New Zealand accordingly capture Māori realities, reflect Māori models of 
health and well-being, and are culturally appropriate (Cram, 2003; Katoa Ltd, n.d.). Usage of pain measurement tools which disregard Māori perspectives may lead to discriminatory practice in Aotearoa New Zealand and further act as a barrier for Māori receiving adequate pain management services. However, there is no body of evidence summarising the key driving factors associated with pain experience for Māori. To address these gaps in the evidence, this systematic review had three objectives. Firstly, to assess studies that have used qualitative research methodologies to understand Māori experiences of pain (objective 1). Secondly, to assess the current evidence of pain assessment tools/questionnaires that have been validated for Māori, capturing their lived pain experiences (objective 2). And thirdly, to propose a framework for evaluating the adherence to kaupapa Māori research (KMR) guidelines (objective 3).

\section{METHODS}

This systematic review was conducted and reported using Preferred Reporting Items for Systematic Reviews and Metaanalyses (PRISMA) guidelines (Moher et al., 2009).

\section{Search strategy}

A comprehensive electronic literature search strategy was developed in consultation with a senior medical librarian at the
University of Otago. Keywords and relevant MeSH headings for objectives 1 and 2 are shown in Tables 1 and 2, respectively. Several exploratory trial searches were carried out to identify relevant search terms. Electronic databases (PubMed, Medline, Scopus, Clinical Key, Web of Science, Embase) were used; supplementary searches were conducted in Google Scholar, and relevant national and international journals (Table 3). Reference lists of the included studies and other grey literature (i.e., materials not published commercially or indexed by electronic databases) were also searched (e.g., nzresearch.org.nz and Te Puna) (University of Otago, 2017).

The original search was performed from inception of the database (search undertaken on 22 December 2017). Autoalerts were created to identify any articles published following the initial search. Other sources were searched that had recommendations on pain assessment procedures endorsed by health professional associations or government agencies (e.g., Physiotherapy New Zealand, New Zealand Pain Society, Faculty of Australasian Pain Medicine, and ACC). A follow-up search was conducted on 24 February 2019 to identify any studies published during the interim period.

Please refer to Appendix A for a glossary of Māori terms that are referred to in this paper.

\section{Table 1}

Key Words and Mesh Terms for Qualitative Studies (Objective 1)

\begin{tabular}{|c|c|c|c|c|}
\hline Population & AND & Methodology & ND & Topic/focus \\
\hline Māori & $\begin{array}{l}0 \\
R\end{array}$ & $\begin{array}{l}\text { Interview } \\
\text { Focus group } \\
\text { Qualitative design } \\
\text { Qualitative method } \\
\text { Consultation } \\
\text { Qualitative research }\end{array}$ & $\begin{array}{l}\mathbf{O} \\
\mathrm{R}\end{array}$ & Pain \\
\hline
\end{tabular}

Table 2

Key Words and MeSH terms for Quantitative Studies (Objective 2)

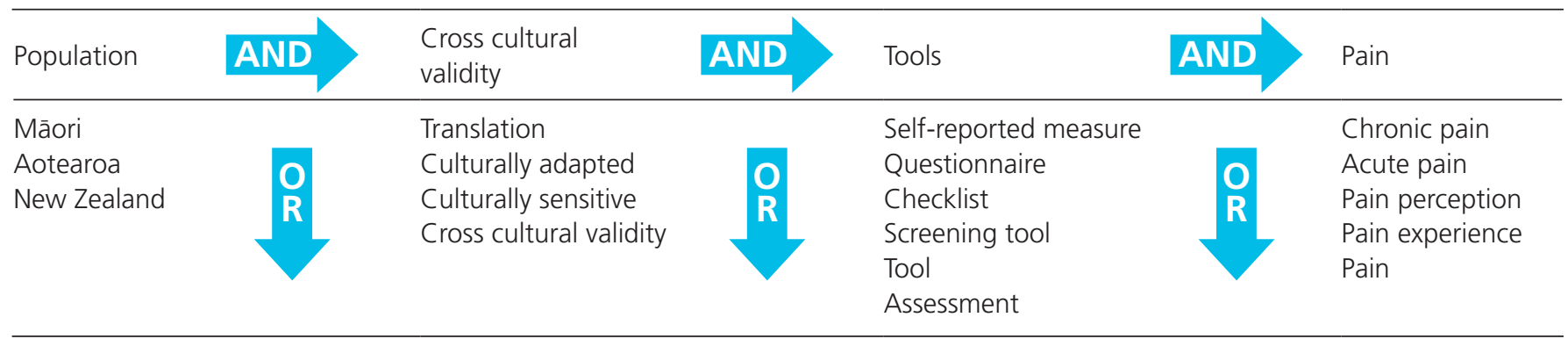


Table 3

Relevant National and International Journals/Pain Educational Resources Searched

Australasian Medical Journals (e.g., New Zealand Medical Journal, The Medical Journal of Australia)

International Journal of Indigenous Health

International Journal of Indigenous Peoples

International Journal of Cultural Studies

Clinical Journal of Pain

Pain

European Journal of Pain

The Journal of Pain

Pain practice

Pain Physician

Journal of Pain and Palliative Care Pharmacotherapy

Journal of Pain and Symptom Management

Journal of Pain Research

Pain Reports

British Journal of Pain

Journal of Aboriginal Health

Pain-ED

Māori Health Review

Social science online publications such as Kōtuitui: New Zealand Journal of Social Sciences Online

\section{Inclusion criteria}

Inclusion criteria for objective 1 were studies that investigated Māori experiences of pain. Such studies must have developed themes on pain experience among Māori using qualitative methodologies. For objective 2, studies were included that investigated cross-cultural validity (CCV) of pain assessment questionnaires assessing pain experience (pain severity/ interference or disability, pain self-efficacy, pain-related cognitions, and affective components). This included questionnaires currently recommended for use in clinical practice in Aotearoa New Zealand (Nationwide Service Framework Library, 2015). Included studies could be peer-reviewed publications or unpublished work (e.g., dissertations and theses, literature reviews, or reports) and be written in English or te reo Māori. Two reviewers evaluated all retrieved citations for inclusion in the study.

\section{Data extraction}

The following were extracted from included studies: author and year, questionnaire investigated, population/participants' characteristics, CCV/qualitative research process, and the findings (including key themes and categories generated from qualitative studies).

\section{Assessment of study quality (risk of bias)}

To assess qualitative studies, an adaptation of the Critical Appraisal Skills Programme (CASP) assessment tool for qualitative studies was used (Critical Appraisal Skills Programme, 2017). CASP applies 10 questions asked systematically, and determines whether the results of the study are valid, what they consist of, and if the results will help for the population of interest (i.e., Māori population).

The COnsensus-based Standards for the selection of health Measurement INstruments (COSMIN) checklist (Terwee et al., 2012) was used to evaluate the methodological quality of those studies that assessed CCV of pain questionnaires. The
COSMIN checklist contains standards for design requirements and preferred statistical methods of studies on the measurement properties of health measurement tools. Utilising the CCV section (box $\mathrm{G}$ ) of the checklist (which evaluates the studies against 15 criteria, graded as "excellent", "good", "fair", or "poor"), we were able to determine the overall quality of CCV of the included studies. A methodological score for CCV was obtained by taking the lowest score of any item in the box (i.e., "worse score counts" algorithm, described by the COSMIN checklist).

Level of adherence to KMR

KMR is a recognised methodology for conducting culturally appropriate research with Māori (Walker et al, 2006). Firstly, we searched the literature to identify whether there were any existing tools to appraise the level of adherence to KMR in the included studies. No evidence of validated tools was found. Therefore, we adapted the Te Ara Tika ethical research guidelines developed by the Health and Research Council (HRC) (Hudson et al., 2010) (Appendix B). Te Ara Tika is a framework used to address Māori ethical issues within the context of decision-making by ethics committee members about proposed research involving Māori. The progressive framework outlines minimum standard, good practice, and best practice for conducting research with Māori. Each standard evaluates elements of whakapapa, tika, manaakitanga, and mana. The "minimum standard" should be met for the research to be approved; "best practice" is the gold standard, in which the values and expectations of the research align with te ao Māori. Te Ara Tika was chosen to be adapted as these guidelines are well referenced and designed, and incorporate key questions which determined how information was gathered with Māori. The guidelines were adapted by changing questions from present to past tense and excluding the "minimum standard", as it was assumed the research project must have met "minimum standard" in order to be undertaken. The 
remaining questions were crossed-checked with the validated Māori research resource Nga Ara Tohutohu Rangahau Māori to ensure relevant concepts were included (Ministry of Social Development, 2004). The level of adherence to KMR was determined by the lowest grade obtained for each principle.

\section{Synthesis of results}

We utilised the Confidence in the Evidence from Reviews of Qualitative research (CERQual) approach to summarise our confidence in the findings across the filtered studies (Glenton et al., 2018). CERQual assesses the confidence in the evidence based on four key components: the methodological limitations of included studies ("the extent to which there are concerns about the design or conduction of the primary studies"), the relevance of the included studies to the review question ("the extent to which the data from the primary studies supporting a review finding is applicable to the context specified in the review question"), the coherence of the review finding ("how clear and cogent the fit is between the data from the primary studies and a review finding that synthesizes that data"), and the adequacy of the data contributing to a review finding ("overall determination of the degree of richness as well as the quantity of data supporting a review finding").

Confidence was judged as "high", "moderate", "low", or "very low". The starting point of "high confidence" suggests that each review finding should be perceived as a reasonable representation of the phenomenon of interest unless there are factors that would weaken this assumption. Finally, the review synthesised both qualitative and quantitative processes, and identified gaps for further development of relevant pain tools for clinical use.

\section{RESULTS}

Following the comprehensive search process, three studies were found to be eligible for inclusion in the review for objective 1 (Fig. 1) (Magnusson \& Fennell, 2011a, 2011b; McGavock, 2011). Key characteristics of these studies are displayed within Table 4. Two publications arose from one study, but were reported as two separate studies (Magnusson \& Fennell, 2011a, 2011b). The age of participants ranged from 32 to 81 years in a sample size of 15 and 33 respectively for each paper (Magnusson \& Fennell, 2011a, 2011b). Pain experiences (e.g., physical pain, emotional

Figure 1

Flowchart of Article Screening Process - Objective 1

\begin{tabular}{|c|}
\hline Identification \\
\hline Screening \\
\hline
\end{tabular}

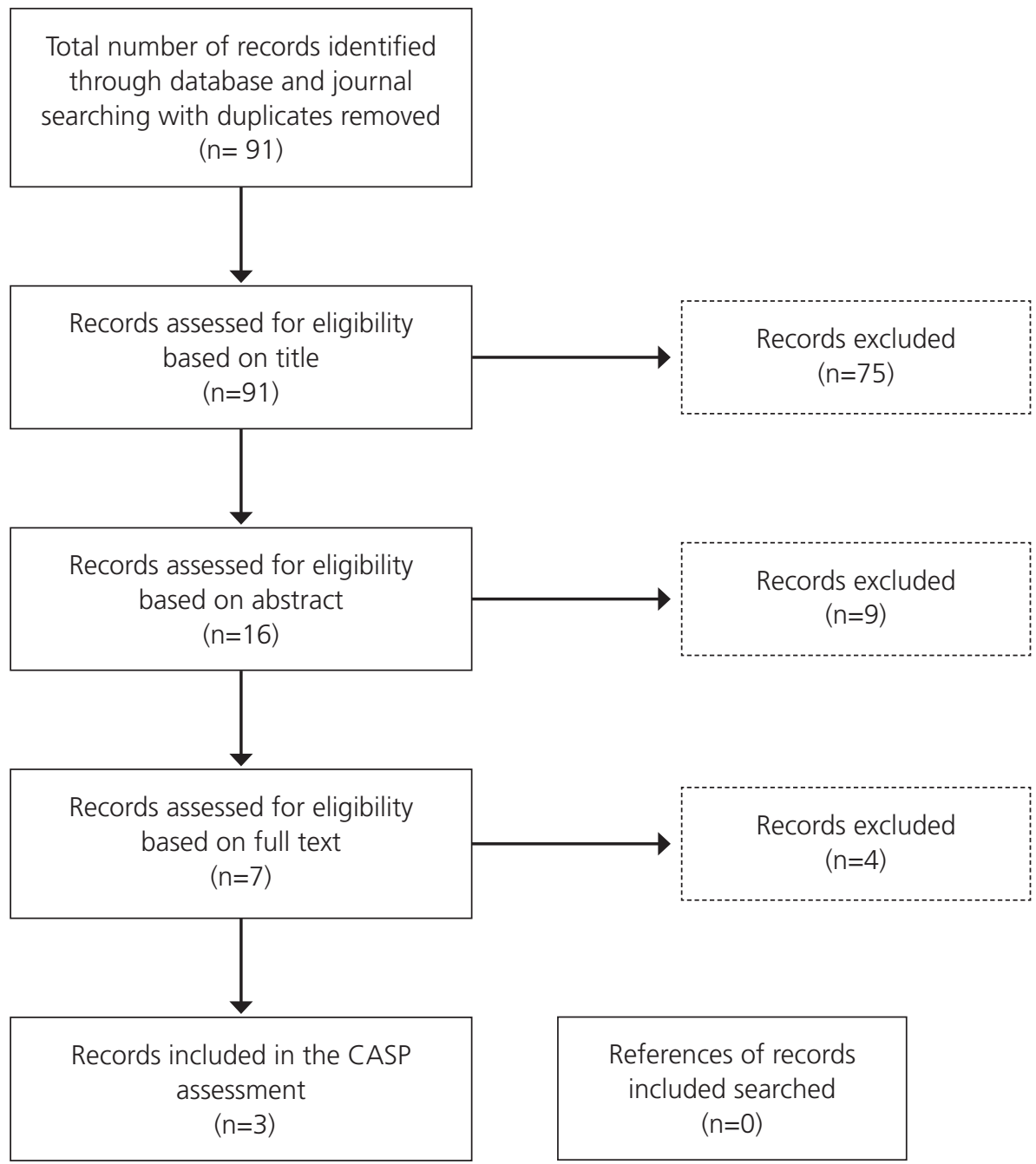


Table 4

Characteristics of Included Studies

\begin{tabular}{|c|c|c|c|}
\hline $\begin{array}{l}\text { Author (year) } \\
\text { Study aims }\end{array}$ & $\begin{array}{l}\text { Participant } \\
\text { characteristics }\end{array}$ & Data collection procedures & Results/findings \\
\hline \multirow{10}{*}{$\begin{array}{l}\text { McGavock (2011) } \\
\text { To conduct an in-depth } \\
\text { exploration of the lived } \\
\text { experiences of Māori who } \\
\text { are currently experiencing } \\
\text { chronic pain or a painful } \\
\text { chronic health condition }\end{array}$} & \multirow{3}{*}{$\begin{array}{l}7 \text { adult Māori } \\
5 \text { female } \\
2 \text { male }\end{array}$} & \multirow{5}{*}{$\begin{array}{l}\text { Face-to-face interview } \\
\text { Adapted interpretative } \\
\text { phenomenological } \\
\text { analysis (IPA) }\end{array}$} & \multirow{2}{*}{$\begin{array}{l}\text { Four superordinate themes identified } \\
\text { 1. A life transformed by the experience of } \\
\text { chronic pain }\end{array}$} \\
\hline & & & \\
\hline & & & 2. Experiences of chronic pain as Māori \\
\hline & Age: $26-52$ years & & 3. Evaluating treatment experiences \\
\hline & $\begin{array}{l}3-25 \text { years }+ \text { of } \\
\text { chronic pain }\end{array}$ & & $\begin{array}{l}\text { 4. Negative perceptions, negative } \\
\text { experiences }\end{array}$ \\
\hline & \multirow{5}{*}{$\begin{array}{l}\text { Varying types of } \\
\text { non-cancer pain }\end{array}$} & & Māori identity and culture \\
\hline & & & $\begin{array}{l}\text { The whānau as a whole was described as a } \\
\text { priority over individual health. }\end{array}$ \\
\hline & & & $\begin{array}{l}\text { Tolerating or pushing through pain for the } \\
\text { sake of others. }\end{array}$ \\
\hline & & & $\begin{array}{l}\text { Able to deal with experiences of chronic pain } \\
\text { and mental illness better if engaged in the } \\
\text { process of whakapapa. }\end{array}$ \\
\hline & & & $\begin{array}{l}\text { Important concepts related to Māori culture, } \\
\text { such as a holistic view of the person and of } \\
\text { well-being, and the influence of spirituality } \\
\text { and religion. }\end{array}$ \\
\hline \multirow{10}{*}{$\begin{array}{l}\text { Magnusson \& Fennell } \\
\text { ( } 2011 \text { a) } \\
\text { To better assess and } \\
\text { treat pain in different } \\
\text { cultures, the perspectives } \\
\text { and experiences of that } \\
\text { culture must be taken into } \\
\text { consideration. Therefore, } \\
\text { the study was undertaken } \\
\text { to better understand Māori } \\
\text { perspectives of pain }\end{array}$} & \multirow{2}{*}{$\begin{array}{l}15 \text { adult Māori } \\
12 \text { female } \\
3 \text { male }\end{array}$} & \multirow{4}{*}{$\begin{array}{l}\text { Adapted versions of the } \\
\text { McGill Pain Questionnaire } \\
\text { and Headache Disability } \\
\text { Inventory } \\
\text { Discussed pain experience } \\
\text { of patients, rather than own } \\
\text { pain experience }\end{array}$} & Descriptive phrases of the experience of pain \\
\hline & & & $\begin{array}{l}56(92 \%) \text { were endorsed by } 65 \% \text { or more of } \\
\text { the participants. }\end{array}$ \\
\hline & \multirow{2}{*}{$\begin{array}{l}\text { (12 Māori } \\
\text { healthcare workers, } \\
3 \text { kaumātua) }\end{array}$} & & $\begin{array}{l}\text { Participants provided } 158 \text { alternatives, } \\
\text { using either alternative wording or phrases. }\end{array}$ \\
\hline & & & Pain descriptors \\
\hline & Age: $32-81$ years & & $\begin{array}{l}123(100 \%) \text { were endorsed by } 65 \% \text { or more } \\
\text { of the participants, with } 77 \text { descriptors }(63 \%)\end{array}$ \\
\hline & \multirow{4}{*}{$\begin{array}{l}15 \text { participants } \\
\text { indicated their } \\
\text { fluency in te reo } \\
\text { Māori } \\
10 \text { basic } \\
3 \text { conversational } \\
2 \text { fluent }\end{array}$} & & being endorsed by $100 \%$ of the participants. \\
\hline & & & $\begin{array}{l}8 \text { alternative descriptors and } 58 \text { additional } \\
\text { descriptors were provided by participants, } \\
97 \% \text { were supplied by healthcare providers. }\end{array}$ \\
\hline & & & $\begin{array}{l}\text { No alternative or additional descriptors } \\
\text { were provided in te reo Māori. }\end{array}$ \\
\hline & & & Terms and phrases of measures commonly \\
\hline & $\begin{array}{l}\text { Purposeful sampling } \\
\text { technique }\end{array}$ & & $\begin{array}{l}\text { used to assess pain appropriately capture } \\
\text { Māori pain experiences. However, it may } \\
\text { be beneficial to confirm the descriptors } \\
\text { used accurately capture experiences being } \\
\text { measured. }\end{array}$ \\
\hline
\end{tabular}




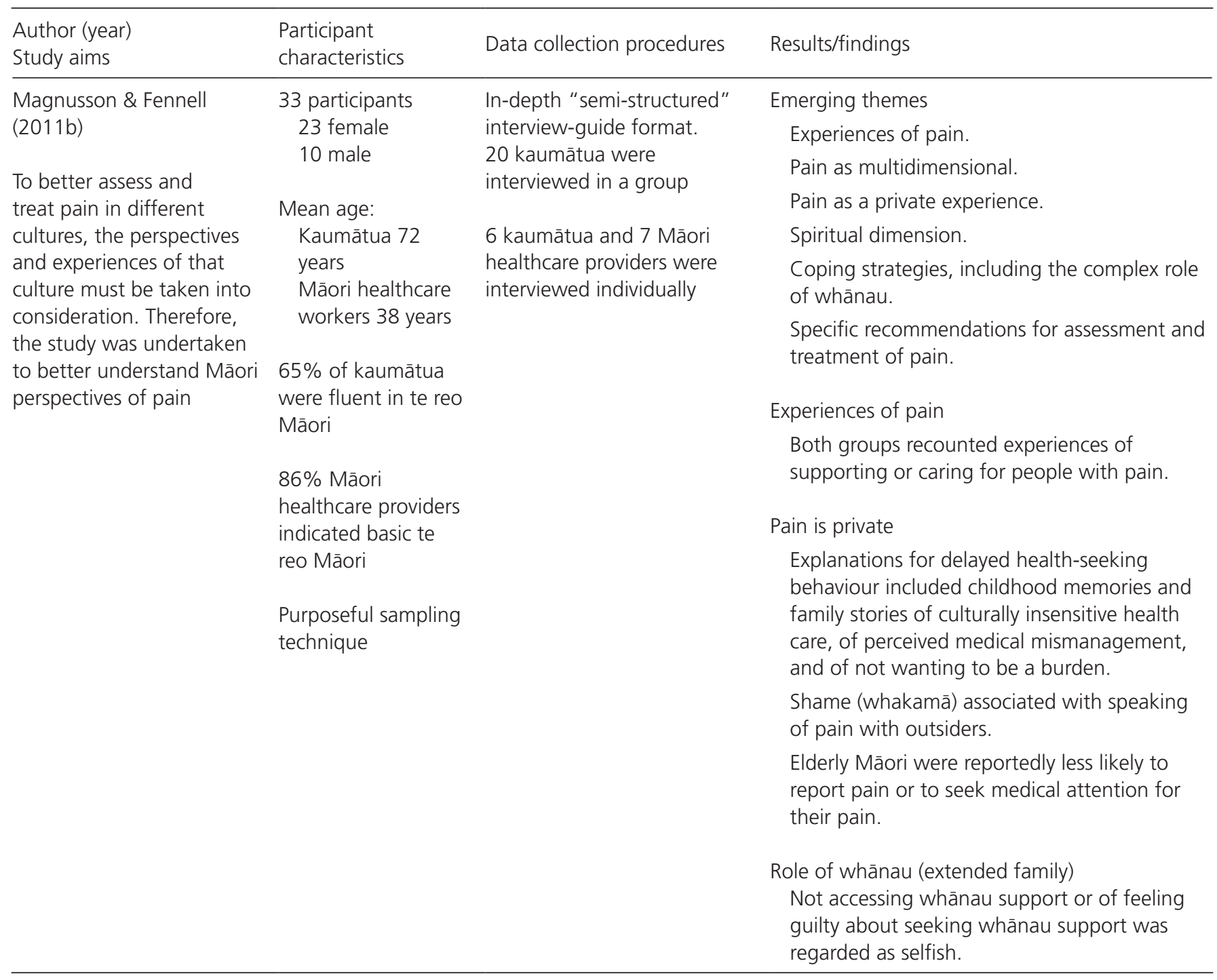

pain, and psychological pain) were reported differently between the papers, including different ways of qualitatively assessing the participants, and therefore, the study results are discussed individually in our research. An adapted pain questionnaire to gather data for appropriateness on pain descriptors (Magnusson \& Fennell, 2011a) and semi-structured focus group interviews (Magnusson \& Fennell, 2011b) were used as well as a faceto-face interview method (McGavock, 2011). No studies were identified for inclusion in the review for objective 2 (Fig. 2). Therefore, further COSMIN-based analysis was not carried out. Neither auto-alerts nor follow-up searches produced any studies eligible to be included in this review.

\section{Quality assessment and evidence synthesis}

CASP

The CASP evaluation determined McGavock's (2011) study on Māori lived experiences of chronic pain as "high quality", scoring 10/10. The paper by Magnusson \& Fennell (2011a) was not appraised using the CASP tool as the data were collected using a self-administered questionnaire rather than an interviewbased approach. However, the study details were included for descriptive analysis. The study of Magnusson \& Fennell (2011b) was determined as "medium-high quality", scoring $7 / 10$, due to missing information from questions 6, 8 and 9 (Table 5).

\section{CERQual}

Based on CERQual evaluation, the overall evaluation demonstrated "high-moderate" confidence in the findings from the included studies. CERQual graded the studies as highmoderate quality due to very minor concerns for methodological limitations, minor concerns for relevance, and very minor concerns for adequacy. Coherence was not discussed, as neither study discussed the same type of pain and limited literature was found. 
Figure 2

Flowchart of Article Screening Process - Objective 2

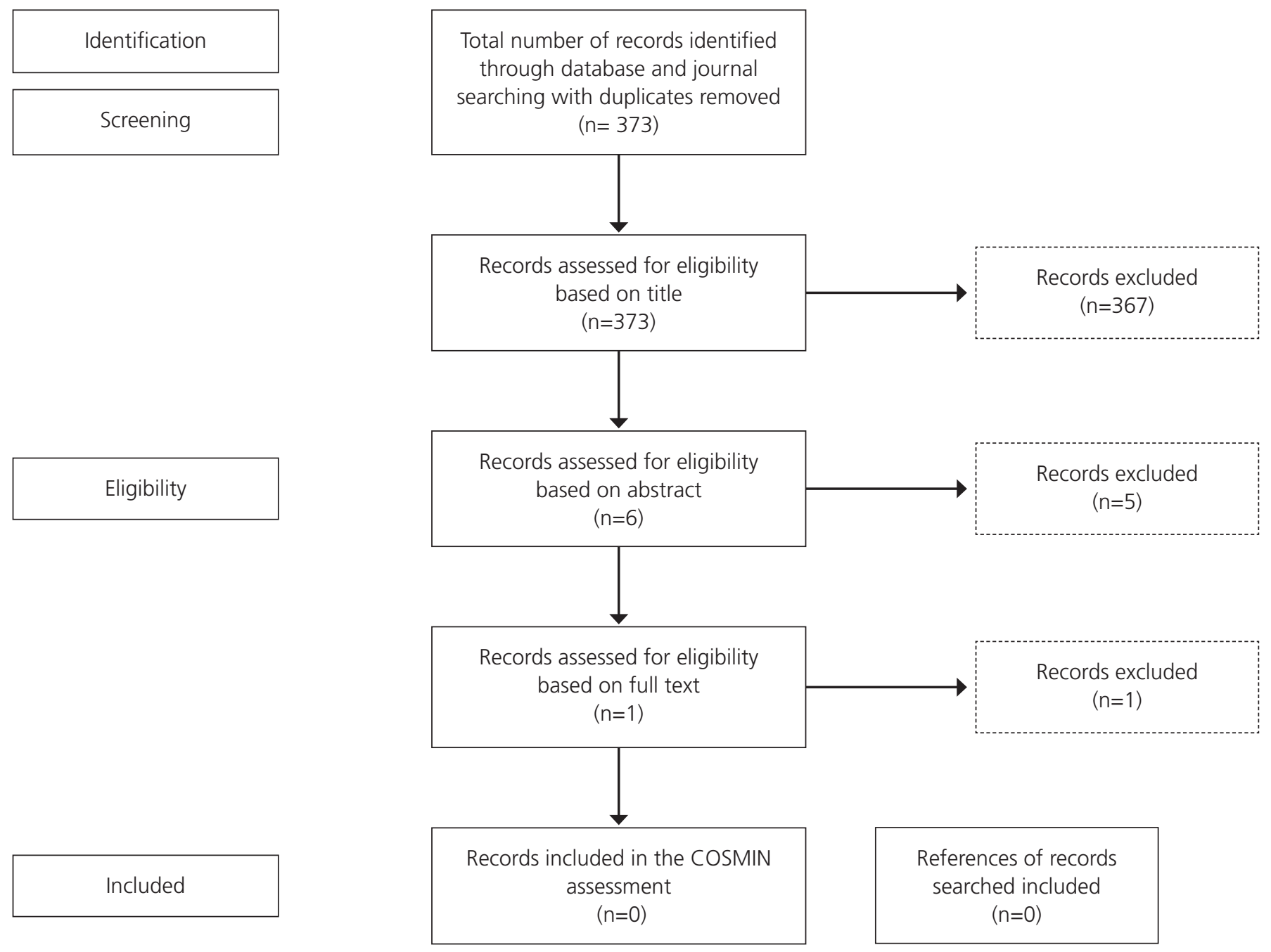

Note. COSMIN = COnsensus-based Standards for the selection of health Measurement INstruments (Terwee et al., 2012).

Table 5

Critical Appraisal Skills Programme Evaluation

Questions and their respective grade (respective page number within text)

\begin{tabular}{|c|c|c|c|c|c|c|c|c|c|c|}
\hline Citation & 1 & 2 & 3 & 4 & 5 & 6 & 7 & 8 & 9 & 10 \\
\hline McGavock (2011) & Yes & Yes & Yes & Yes & Yes & Yes & Yes & Yes & Yes & Yes \\
\hline Magnusson \& Fennell (2011a) & YES & NA & NA & NA & NA & NA & NA & NA & NA & NA \\
\hline Magnusson \& Fennell (2011b) & Yes & Yes & Yes & Yes & Yes & NA & Yes & NA & NA & Yes \\
\hline
\end{tabular}

Note. $\mathrm{NA}=$ not applicable. 


\section{Adherence to KMR}

Based on evaluation using the adapted guidelines, the overall assessment for both studies was of "minimal standard" (Table 6).

\section{DISCUSSION}

This systematic review has not identified any pain assessment tools that have been specifically developed for capturing Māori experiences of pain in Aotearoa New Zealand or cross-culturally validated with Māori. However, two studies were found that used qualitative research methodologies to understand Māori experiences of pain. Themes and meta-themes from both studies discuss whānau, Māori holistic views of health, spirituality, and whakapapa as being associated with pain experience.

Whānau play an important role when Māori are experiencing pain (McGavock, 2011; Magnusson \& Fennell, 2011 b).

McGavock (2011) noted from participants: "Tolerating pain and push through for the sake of others" (p. 79) and "Individuals would rather spend money and time on healthcare for whānau rather than for themselves" (p. 79). These points showcase how many Māori are very relationship orientated and view themselves as part of a larger community. The needs of others are often more important than their own, emphasising that rather than an individualised approach to pain management for Māori, whānau are often an important aspect and, therefore, may need to be included in the physiotherapy treatment process. Magnusson \& Fennell (2011b) also noted that if whānau were not involved during pain experiences, Māori were regarded as being "selfish" (p. 47), both personally and in relation to others in their whānau. Whānau involvement was viewed as a way of promoting motivation for adherence to treatment interventions, which is a large issue in physiotherapy management. Whānau were also seen as health advocates for Māori who felt less comfortable discussing their pain with healthcare providers, as the healthcare provider was often found to be "insensitive of cultural practises" (Magnusson \& Fennell, 2011b, p. 47). Other studies have shown similar results, discussing the importance of family and its effect on pain experience (Cram, 2003; Hughes et al., 2014; Hung et al., 2017; Richmond et al., 2007). On this basis, it is clear that the individual's relationship with whānau can impact on their experience of pain, and therefore, should be an essential consideration of pain assessment within physiotherapy clinical practice.
Magnusson \& Fennell (2011b) and McGavock (2011) discuss Māori experiences of pain as being multidimensional with physical, mental, spiritual, and social aspects of health all being affected. Differing ethnic and cultural groups often have their own ways of describing, experiencing, and managing pain (Peacock \& Patel, 2008). Based on Māori clinicians and whānau perspectives of health, McGavock (2011) discusses how initially the effects of pain may be seen in physical health but are also seen to affect spiritual and mental health, and relationships with whānau. This may be due to physical health being the most noticeable and often the first aspect assessed in a physiotherapy assessment. Other studies also discuss these Māori holistic views of health (Cram, 2003; Mark \& Lyons, 2010) and its importance for many Māori when it comes to understanding how health can be affected during illness. This illustrates the importance within physiotherapy in Aotearoa New Zealand to incorporate conversations around a Māori holistic view of health during clinical pain assessments. This may help to better capture the effects of pain for Māori as a whole and provide specific treatment in these areas. Addressing aspects included within Māori models of health, such as Te Whare Tapa Whā (Durie, 1985), may be an option to ensure Māori holistic views of health are explored during pain assessment.

Spirituality is an important concept of health within Māori (Durie, 1994; McGavock, 2011). Having a sense of spirituality and religion have also been shown to affect psychological well-being, including reducing pain and fatigue among various pain conditions (Dedeli \& Kaptan, 2013). Multiple participants acknowledged spirituality in McGavock's (2011) study, discussing its importance and how it led them to utilise traditional methods of healing. Some participants also discussed how modern healthcare providers do not believe in traditional ways of healing, which made them feel as though the healthcare provider "didn't care" and, therefore, impacted negatively on their rapport with the doctor: "She's (Doctor) not open to alternative medicine, anything even the name Arnica [homeopathic remedy for muscle aches and bruises] she'll probably just sort of raise an eyebrow you know" (p. 82). As a physiotherapist, it is important to seriously acknowledge Māori views of spirituality as a management and coping strategy of pain. Ignoring patient beliefs may only prolong recovery and reduce the success of pain management strategies (Hansson, 2011). In order to deliver physiotherapy services with the appropriate level of understanding of spiritual needs for Māori,

Table 6

Adherence to Kaupapa Māori Research Methodology

\begin{tabular}{llllll}
\hline & & \multicolumn{3}{c}{ Tikanga principle and level of engagement (minimal, good or best practice) ${ }^{\text {a }}$} \\
\hline Author (year) & Whakapapa & Tika & Manaakitanga & Mana & Overall impression \\
\hline McGavock (2011) & Best & Good & Good & Minimal & Minimal \\
Magnusson \& Fennell & Minimal & Minimal & Good & Minimal & Minimal \\
$(2011 a, 2011 b)$ & & & & \\
\hline
\end{tabular}

a Refer to Appendix B for full definitions and the criteria for grading - "best", "good", and "minimal". 
it also requires the health professions and health "system" to upskill in their understanding of Māori perspectives of hauora Māori.

Whakapapa is discussed by McGavock (2011), as it is an important concept of health within Māori worldviews. One participant said, "She may have been able to deal with chronic pain better if she engaged in the process of Whakapapa" ( $p$. 80). Understanding one's culturally specific beliefs, attitudes, and knowledge of pain has been shown to affect people's experience of pain (Shipton, 2013). From a Māori perspective, understanding one's whakapapa or ancestry may be important for pain assessment questionnaires being purposefully developed for Māori. For an individual managing their own experience of pain, having a sense of belonging may be empowering, giving them mana to manage their chronic pain.

This review failed to identify any pain assessment questionnaires that have been developed purposefully for Māori, and/or questionnaires that have undergone CCV assessment in this population. People who experience chronic pain in Aotearoa New Zealand are often asked to complete the electronic Persistent Pain Outcomes Collaboration (ePPOC) questionnaires at the start of assessment and during follow-up periods of receiving health services to manage their pain (Lovibond et al., 1995; Nicholas, 1989; Reilly et al., 1993; Sullivan, 1995). The lack of evidence of culturally valid pain tools indicates that pain assessment frameworks used in Aotearoa New Zealand may not be capturing Māori perspectives of pain. Similarly, a previous study challenged the CCV of the SF-36 questionnaire, in particular, the ability of SF-36 to differentiate mental and physical component scores in older Māori (i.e., > 45 years) (Scott et al., 2000). The current findings suggest a need for a culturally sensitive pain assessment framework to be developed for measuring pain in the Māori population.

There are limitations in the included qualitative studies which impact the validity of the results of this study. For example, discussion of the authors' role within the research, potential bias, influence on the study, and arguments against the results were not discussed. Adherence was determined to be of a minimal standard for both studies. However, the results of this evaluation should be interpreted with caution, as the tool adapted for the purpose of this review needs to be further validated. The included studies were determined to be of high-moderate confidence due to minor concerns with methodological limitations (reflexivity was not discussed by Magnusson \& Fennell 2011a, 2011b). There were also minor concerns about relevance, as participants from McGavock's (2011) study were recruited from one iwi, and very minor concerns with adequacy due to all three studies having limited quantities of data, yet the data were rich. Coherence was not evaluated as studies discussed different pain types. Magnusson \& Fennell (2011a) suggest that current pain measuring tools are sufficient in capturing Māori experiences of pain, but we propose that themes associated with Māori lived experiences of pain need to be integrated for a more effective and holistic approach to pain assessment which is culturally responsive.

Reflexivity allows the reader to gain insight into how the researcher impacted the study from their existing knowledge and perception. For McGavock (2011), the following is unclear: whether she is of Māori descent (she stated that she had an "...insider status as a Māori..." [p. 108]), the nature of her affiliation with the iwi/hapū or area, and the extent of her knowledge regarding tikanga Māori. This information is required to determine the quality of $\mathrm{KMR}$, and without this, it is hard to ascertain the validity of the data collected. For example, would Māori who were interviewed feel confident enough to share personal information regarding their experiences of pain with someone of non-Māori descent? Magnusson and Fennell (2011a) did not report on reflexivity within the study, and the sample size was small, consisting of only kaumātua and Māori healthcare providers. Themes developed from a small sample size study and from one iwi within Aotearoa New Zealand may not accurately represent the wide diversity of Māori within Aotearoa New Zealand (McGavock, 2011).

The evaluation of the studies using the adapted kaupapa Māori tool rated the acceptability of both studies as "minimal". This means that the research conducted with Māori did not follow tikanga Māori for conducting research. It is important that research conducted with Māori follows tikanga Māori, so Māori feel comfortable and safe to share their experiences with the researcher. Otherwise, information collected may lack depth and validity, and inaccurately represent Māori interviewed. Although the tool we developed needs to be validated, it does provide a starting point for assessment of the external validity of research undertaken with Māori. There are guidelines on how research should be conducted with Māori; however, there is no tool to determine how well research was conducted in regard to tikanga Māori.

As there are no culturally valid pain questionnaires for Māori, it is important to approach assessment with an holistic view of health. It is essential that concepts of whānau, whakapapa, and spirituality are incorporated for better understanding and the ability to respond more appropriately to the wider context of chronic pain in Māori populations. Clinically, ACC as a funder of pain services, requires patients with pain to undergo initial assessment using the ePPOC questionnaires, which include the Depression Anxiety Stress Scale, Pain Self-Efficacy Questionnaire, and the Pain Catastrophizing Scale. None of the three questionnaires specifically incorporate questions addressing whānau, spirituality, whakapapa, or other Māori holistic views of health. Items in the questionnaires reflecting these themes should be included within ePPOC to better assess Māori experiences of pain and, therefore, provide more effective care for Māori. However, further research is required to develop or adapt a pain questionnaire that is culturally valid for Māori. It is important that the key themes identified here are explored further using kaupapa Māori qualitative research, and the outcomes incorporated within future development and validation of pain assessment tools. These aspects are shown to be an integral part of Māori culture, which provide insight into how pain experience is multidimensional. Aspects of the COSMIN checklist should be used when creating these pain assessment tools and questions that are specific to the themes above. Examples of this might include describing how the translation from Māori to English was achieved, including expertise within Māori communities (i.e., kaumātua); 
formulating questions based on Māori experiences of pain; and having multiple reviews of the questionnaire with Māori to ensure relevance. The assessment tools should also be tested and validated with Māori from throughout Aotearoa New Zealand and reviewed iteratively due to the wide diversity of Māori.

This systematic review included a small number of papers, which is consistent with the proposed narrow research question. This allowed for an arguably meaningful outcome. Furthermore, specificity of the search terms was used to highlight the gap in the literature and the need for culturally valid pain questionnaires, while also trying to capture valid Māori experiences of chronic pain. An implication of this is that literature may have been missed which could have provided further insight into the experiences of Māori with chronic pain.

\section{CONCLUSION}

With no questionnaire or assessment tool that is culturally sensitive for capturing Māori experiences of pain, a validated measurement tools encompassing the themes identified needs to be developed in order to accurately capture themes which better reflect Māori experiences of pain. A culturally valid pain measurement tool would provide a holistic view and the ability to identify areas affected by pain which cannot be captured in a westernised pain measurement tool. It would, therefore, allow physiotherapists to offer specific support and care in these areas previously overlooked, may allow better use of resources for Māori, and may also provide a talking point for physiotherapists less comfortable or knowledgeable about the KMT.

\section{KEY POINTS}

1. There are no culturally valid pain questionnaires for the Māori population.

2. The key themes of whānau, Māori holistic views of health, whakapapa, and spirituality need to be incorporated within pain assessment.

3. More qualitative research using KMR guidelines is required to discover other key themes which may capture Māori experiences of pain.

\section{DISCLOSURES}

Mr Tobias Hoeta was supported by a Health Research Council Māori Health Summer Research Scholarship (2017/2018).

\section{PERMISSIONS}

None.

\section{ACKNOWLEDGEMENTS}

We would like to thank Thelma Fisher (Physiotherapy Subject Librarian, University of Otago) for her assistance in developing a comprehensive search strategy. Thanks also to the Centre for Health, Activity, and Rehabilitation Research for supporting this project.

\section{ADDRESS FOR CORRESPONDENCE}

Tobias J. Hoeta, undergraduate student, School of Physiotherapy, University of Otago, Dunedin 9054, New Zealand.

Email: hoeto357@student.otago.ac.nz

\section{REFERENCES}

Brady, B., Veljanova, I., \& Chipchase, L. (2016). Culturally informed practice and physiotherapy. Journal of Physiotherapy, 62(3), 121-123. https://doi. org/10.1016/j.jphys.2016.05.010

Brady, B., Veljanova, I., \& Chipchase, L. (2016). Are multidisciplinary interventions multicultural? A topical review of the pain literature as it relates to culturally diverse patient groups. Pain, 157(2), 321-328. https:// doi.org/10.1097/j.pain.0000000000000412

Breivik, H., Borchgrevink, P. C., Allen, S. M., Rosseland, L. A., Romundstad, L., Breivik Hals, E. K., Kvarstein, G., \& Stubhaug, A. (2008). Assessment of pain. British Journal of Anaesthesia, 101(1), 17-24. https://doi. org/10.1093/bja/aen 103

Briggs, A. M., Cross, M. J., Hoy, D. G., Sànchez-Riera, L., Blyth, F. M., Woolf, A. D., \& March, L. (2016). Musculoskeletal health conditions represent a global threat to healthy aging: A report for the 2015 World Health Organization World Report on Ageing and Health. The Gerontologist, 56(Suppl 2), S243-S255. https://doi.org/10.1093/geront/gnw002

Cram, F,. Smith, L., \& Johnstone, W. (2003). Mapping the themes of Māori talk about health. New Zealand Medical Journal, 116(1170).

Critical Appraisal Skills Programme. (2017). Qualitative research checklist 13.03.17. http://docs.wixstatic.com/ugd/dded87_25658615020e427da19 4a325e7773d42.pdf

Dedeli, O., \& Kaptan, G. (2013). Spirituality and religion in pain and pain management. Health Psychology Research, 1(3), e29. https://doi. org/10.4081/hpr.2013.e29

Durie, M.H. (1994). Whaiora; Māori health development. Oxford University Press. (pp. 69-75).

Durie, M. H. (1985). A Maori perspective of health. Social Science \& Medicine, 20(5), 483-486. https://doi.org/10.1016/0277-9536(85)903636

Glenton, C., Carlsen, B., Lewin, S., Munthe-Kaas, H., Colvin, C. J., Tunçalp, Ö., Bohren, M. A., Noyes, J., Booth, A., Garside, R., Rashidains, A., Flottorp, S. \& Wainwright, M. (2018). Applying GRADE-CERQual to qualitative evidence synthesis findings - paper 5: how to assess adequacy of data. Implementation Science, 13(Suppl 1), 14. https://doi.org/10.1186/ s13012-017-0692-7

Green, C. R., Anderson, K. O., Baker, T. A., Campbell, L. C., Decker, S., Fillingim, R. B., Kalauokalani, D. A., Lasch, K. E., Myers, C., Tait, R. C., Todd, K. H., \& Vallerand, A. H. (2003). The unequal burden of pain: Confronting racial and ethnic disparities in pain. Pain Medicine, 4(3), 277-294. https://doi.org/10.1046/j.1526-4637.2003.03034.x

Harris, R., Tobias, M., Jeffreys, M., Waldegrave, K., Karlsen, S., \& Nazroo, J. (2006). Effects of self-reported racial discrimination and deprivation on Māori health and inequalities in New Zealand: Cross-sectional study. Lancet, 367(9527), 2005-2009. https://doi.org/10.1016/S01406736(06)68890-9

Hansson, K. S., Fridlund, B., Brunt, D., Hansson, B., \& Rask, M. (2011). The meaning of the experiences of persons with chronic pain in their encounters with the health service. Scandinavian Journal of Caring Sciences, 25(3), 444-450. https://doi.org/10.1111/j.14716712.2010.00847.x

Hudson, M., Milne, M., Reynolds, P., Russell, K., \& Smith, B. (2010). Te Ara Tika guidelines for Maori research ethics: $A$ framework for researchers and ethics committee members. Health Research Council of New Zealand. https://www.hrc.govt.nz/sites/default/files/2019-06/Resource\%20 Library\%20PDF\%20-\%20Te\%20Ara\%20Tika\%20Guidelines\%20for\%20 Maori\%20Research\%20Ethics_0.pdf 
Hughes, S., Jaremka, L. M., Alfano, C. M., Glaser, R., Povoski, S. P., Lipari, A. M., Agnese, D. M., Farrar, W. B., Yee, L. D., Carson, W. E., Malarkey, W. B., \& Kiecolt-Glaser, J. K. (2014). Social support predicts inflammation, pain, and depressive symptoms: Longitudinal relationships among breast cancer survivors. Psychoneuroendocrinology, 42, 38-44. https://doi.org/10.1016/j. psyneuen.2013.12.016

Hung, M., Bounsanga, J., Voss, M. W., Crum, A. B., Chen, W., \& Birmingham, W. C. (2017). The relationship between family support; pain and depression in elderly with arthritis. Psychology, Health \& Medicine, 22(1), 75-86. https://doi.org/10.1080/13548506.2016.1211293

Linton, S. J., \& Shaw, W. S. (2011). Impact of psychological factors in the experience of pain. Physical Therapy, 91(5), 700-711. https://doi. org/10.2522/ptj.20100330

Lovibond, S. H., Lovibond, P. F., \& Psychology Foundation of Australia. (1995). Manual for the depression anxiety stress scales. Psychology Foundation of Australia.

Katoa Ltd (n.d.). Kaupapa Māori research. http://www.katoa.net.nz/kaupapamaori

Magnusson, J. E., \& Fennell, J. A. (2011a). Understanding the role of culture in pain: Māori practitioner perspectives of pain descriptors. New Zealand Medical Journal, 124(1328), 30-40.

Magnusson, J. E., \& Fennell, J. A. (2011b). Understanding the role of culture in pain: Māori practitioner perspectives relating to the experience of pain. New Zealand Medical Journal, 124(1328), 41-51.

Mark, G. T., \& Lyons, A. C. (2010). Māori healers' views on wellbeing: The importance of mind, body, spirit, family and land. Social Science \& Medicine, 70(11), 1756-1764. https://doi.org/10.1016/j socscimed.2010.02.001

McGavock, Z. C. (2011). A life transformed: the lived experiences of Māori with chronic pain. [Masters of Science in Health Psychology thesis, Massey University]. https://mro.massey.ac.nz/bitstream/handle/10179/3430/02_ whole.pdf?sequence=1\&isAllowed=y

Ministry of Health. (2015). Annual update of key results 2014/15: New Zealand Health Survey. Minsitry of Health. https://www.moh.govt.nz/ notebook/nbbooks.nsf/0/997AF4E3AAE9A767CC257F4C007DDD84/\$file/ annual-update-key-results-2014-15-nzhs-dec15-1.pdf

Ministry of Social Development. (2004). Guidelines for research and evaluation with Māori. http://www.msd.govt.nz/documents/aboutmsd-and-our-work/publications-resources/planning-strategy/guidelinesresearch-evaluation-maori/guidlines-research-evaluation-maori.pdf

Moher, D., Liberati, A., Tetzlaff, J., \& Altman, D. G; PRISMA Group. (2009). Preferred reporting items for systematic reviews and meta-analyses: The PRISMA statement. Journal of Clinical Epidemiology, 62(10), 1006-1012. https://doi.org/10.1016/j.jclinepi.2009.06.005

Nationwide Service Framework Library. (2015). Specialist medical services specifications, pain management service. https://nsfl.health.govt.nz/ service-specifications/current-service-specifications/specialist-medicalservices-specifications

Nicholas, M. K. (1989, April 4). Self-efficacy and chronic pain [Conference presentation]. Annual Conference of the British Psychological Society, St. Andrews, Scotland.
Peacock, S., \& Patel, S. (2008). Cultural influences on pain. Reviews in Pain, 1(2), 6-9. https://doi.org/10.1177/204946370800100203

Pitama, S., Huria, T., Beckert, L., \& Lacey, C. (2011). Assessing the assessment: Cultural competence and understandings of pain. New Zealand Medical Journal, 124(1328), 10-12.

Reilly, M. C., Zbrozek, A. S., \& Dukes, E. M. (1993). The validity and reproducibility of a work productivity and activity impairment instrument. Pharmacoeconomics, 4(5), 353-365. https://doi.org/10.2165/00019053199304050-00006

Richmond, C. A. M., Ross, N. A., \& Egeland, G. M. (2007). Social support and thriving health: A new approach to understanding the health of indigenous Canadians. American Journal of Public Health, 97(10), 18271833. https://doi.org/10.2105/AJPH.2006.096917

Rochford, T. (2004). Whare Tapa Wha: A Māori model of a unified theory of health. Journal of Primary Prevention, 25(1), 41-57. https://doi. org/10.1023/B:JOPP.0000039938.39574.9e

Sandelowski, M. (1995). Sample size in qualitative research. Research in Nursing \& Health, 18(2), 179-183. https://doi.org/10.1002/ nur.4770180211

Scott, K. M., Sarfati, D., Tobias, M. I., \& Haslett, S. J. (2000). A challenge to the cross-cultural validity of the SF-36 health survey: Factor structure in Māori, Pacific and New Zealand European ethnic groups. Social Science \& Medicine, 51(11), 1655-1664. https://doi.org/10.1016/s02779536(00)00083-6

Shipton, E. A. (2013). The pain experience and sociocultural factors. New Zealand Medical Journal, 126(1370)

Smith, E., Hoy, D. G., Cross, M., Vos, T., Naghavi, M., Buchbinder, R., Woolf, A. D., \& March, L. (2014). The global burden of other musculoskeletal disorders: Estimates from the Global Burden of Disease 2010 study. Annals of the Rheumatic Diseases, 73(8), 1462-1469. https://doi.org/10.1136/ annrheumdis-2013-204680

Sullivan, M. J. L., Bishop, S. R., \& Pivik, J. (1995). The Pain Catastrophizing Scale: Development and validation. Psychological Assessment, 7(4), 524 532. https://doi.org/10.1037/1040-3590.7.4.524

Terwee, C. B., Mokkink, L. B., Knol, D. L., Ostelo, R. W. J. G., Bouter, L. M., \& de Vet, H. C. W. (2012). Rating the methodological quality in systematic reviews of studies on measurement properties: a scoring system for the COSMIN checklist. Quality of Life Research, 21(4), 651-657. https://doi. org/10.1007/s11136-011-9960-1

University of Otago. (2017). Grey literature in health: Home. https://otago. libguides.com/greylit-health

Walker, S., Eketone, A., \& Gibbs, A. (2006). An exploration of kaupapa Māori research, its principles, processes and applications. International Journal of Social Research Methodology, 9(4), 331-344. https://doi. org/10.1080/13645570600916049 


\section{Appendix A}

\section{Glossary of Māori Terms}

Hapū = sub-tribe

Hauora Māori = Māori view of health

Iwi = tribe

Kaupapa Māori = the Māori way of doing things

Kaumātua $=$ respected Māori elder (male or female)

Manaakitanga $=$ the process of showing respect, generosity, and care for others. Cultural and social responsibilities ${ }^{a}$

Mana $=$ prestige/power/influential qualities. Justice and equity ${ }^{a}$

Mana whakahaere = governance/ authority/power

Māori $=$ the indigenous people of Aotearoa New Zealand

Matāwaka = Māori living within the area who are not related to the local iwi

Māturanga $=$ knowledge/ education

Nga Ara Tohutohu Rangahau Māori = Guidelines for research and evaluation with Māori

Te Ara Tika = guidelines for Māori research ethics

Te ao Māori = the Māori world

Te reo Māori = the Māori language

Te Whare Tapa Whā = the four-sided house (Durie's model of health)

Tika = right/appropriate. Research design ${ }^{\mathrm{a}}$

Tikanga Māori = Māori customs

Whānau = family

Whakapapa $=$ genealogy. Relationships ${ }^{\text {a }}$

Whenua $=$ land $/$ placenta

${ }^{a}$ How the standard is translated in the Te Ara Tika framework. 


\section{Appendix}

\section{Kaupapa Māori Research Grading Tool a}

Principle/question Assessment outcome

1. Whakapapa

Good practice

1a. What is the evidence for engagement with Māori and what was the shape, time scale, and extent of this?

1b. How has the consent issue been dealt with, and is the mode of informed consent suggested appropriate?

Best Practice

1c Is the use of kaupapa Māori research approach evidenced right through the research?

1d What degree of meaningful input have Māori had in influencing the shape of the research?

1e Are Māori participants and their iwi, hapū, and whānau the prime recipients or contributors of results?

If What mechanisms are in place to optimise benefits to participants?

$1 \mathrm{~g}$ Is there an adequate monitoring mechanism?

2. Tika

Good practice

2a How were Māori involved in this project? As researchers, participants, advisors?

2b How did this research project benefit Māori in all of the above?

Best practice

2c Was there adequate participation of Māori in different stages of the research project, including research design, analysis, and dissemination of the results?

2d Who defined the research problem?

2e For whom was the study worthy and relevant, and who said so?

2f What knowledge has the community gained from this study?

$2 \mathrm{~g}$ What were the positive outcomes from this study?

$2 \mathrm{~h}$ To whom is the researcher accountable?

$2 \mathrm{i}$ What processes were in place to support the research, the researched, and the researcher?

3. Manaakitanga

Good practice

3a Were Māori values or concepts used within this research project?

3b How were Māori protocols observed as part of the research project?

3c Were whānau able to support participants within this project?

Best practice

3d Were kaumātua required to guide the research team?

3e How did researchers ensure the safe application of protocols?

4. Mana

Good practice

4a Who benefited from the research, and how was this evidenced?

$4 \mathrm{~b}$ Were the contributions of mana whenua acknowledged?

4c Was there evidence of mana whenua goals, aspirations, development, or expectations? How were these measured and by whom?

$4 d$ Where was the research developed and undertaken, and with whom?

$4 \mathrm{e} \quad$ Has there been engagement with mana whenua, and in what capacity?

4f To whom must the researchers report back to besides funders/institutions?

$4 \mathrm{~g}$ What and where is the relevance to/for Māori in their ongoing development in this research?

$4 \mathrm{~h}$ Does the research include the achievement of Māori goals as an outcome? 
Best practice

$4 \mathrm{i}$ Was there evidence of engagement in a meaningful relationship with mana whenua, or iwi researchers?

4j How does this application protect Māori intellectual property?

4k Was consent gained to access/use mātauranga Māori?

4l How was data ownership guaranteed under mana whakahaere?

$4 \mathrm{~m}$ Whose intellectual property did this research become?

$4 \mathrm{n}$ Has mātauranga Māori contributed to the research, and how was this evidenced?

40 Who owns the data produced/collected/generated during the research?

Note. Adapted this tool for the purpose of this research.

a Refer to methodological section for discussion of adherence to KMR.

b Each principle has an associated grade: either "good" or "best" or "minimal". If the principle did not meet either the "good" or "best" grade, it was regarded as "minimal". 